\title{
Caracterização de pellets produzidos a partir de capim-elefante para uso energético
}

\author{
Mateus Alves de Magalhães ${ }^{1 \star}$, Danilo Barros Donato ${ }^{1}$, Wagner Davel Canal ${ }^{1}$, Angélica de Cássia \\ Oliveira Carneiro ${ }^{1}$, Bárbara Luísa Conrradi Pereira ${ }^{1}$, Benedito Rocha Vital ${ }^{1}$ \\ ${ }^{1}$ Departamento de Engenharia Florestal, Universidade Federal de Viçosa (UFV), Viçosa, Brasil.
}

\begin{abstract}
RESUMO O objetivo deste trabalho foi caracterizar o potencial do capim-elefante (Pennisetum purpureum Schum) para produção de pellets. Inicialmente, a biomassa relativa à gramínea foi caracterizada por meio da determinação da umidade de equilíbrio higroscópico, densidade a granel, poder calorífico superior e teor de cinzas. Os pellets foram produzidos a partir de diferentes teores de umidade $(10,12,14$ e $16 \%$ em base seca) da biomassa. Posteriormente, foi determinado a umidade de equilíbrio higroscópico, a densidade a granel, o poder calorífico superior, o teor de cinzas, o diâmetro e comprimento, a durabilidade mecânica e finos, estimado o poder calorífico útil e a densidade energética dos pellets. Os resultados obtidos foram comparados com a norma europeia de qualidade de pellets não madeira. A peletização promoveu um aumento significativo da densidade a granel, ocasionando um aumento na densidade energética. De modo geral, as partículas de capim-elefante com 12\% de umidade proporcionaram a produção de pellets com melhores propriedades físicas, químicas, mecânicas e com maior densidade energética. Por fim, conclui-se que o capim-elefante apresenta grande potencial para produção de pellets, necessitando de novos estudos com o uso de aditivos ou técnicas de pré-tratamento das partículas que aumentem a densidade a granel e a durabilidade dos pellets.
\end{abstract}

Palavras-chave: gramínea, biomassa, densidade energética.

\section{Characterization of pellets produced from elephant grass for energy use}

\begin{abstract}
The aim of this study was to characterize the potential of elephant grass (Pennisetum purpureum Schum) for pellet production. First, the biomass was characterized by determining the moisture equilibrium moisture content, bulk density, high heating value and ash content. The pellets were produced from different moisture contents $(10,12,14$ and $16 \%$ on a dry basis) of biomass. Then, moisture equilibrium moisture content, bulk density, high heating value, ash content, diameter and length, mechanical durability and fines, estimated net calorific value and energy density of the pellets were determined The results were compared to the European standard of pellets quality not wood. The pelleting process promoted a significant increase in bulk density, leading to an increase in energy density. In general, the elephant grass particles with $12 \%$ humidity provided the production of pellets with better physical, chemical and mechanical properties and higher energy density. The elephant grass has great potential for production of pellets and new studies are necessary to understand the use of additives or pretreatment of particles techniques to increase the bulk density and durability of the pellets.
\end{abstract}

Keywords: grassy, biomass, energy density.

\section{Introdução}

A biomassa de origem vegetal apresenta grande potencial como fonte energética alternativa aos combustíveis fósseis, onde tem ganhado importância, principalmente, devido às pressões impostas pelas organizações e órgãos governamentais no sentido de diminuir o uso de combustíveis oriundos de fontes não renováveis (STREZOV et al., 2008). No intuito de reduzir a dependência dos combustíveis fósseis, tem-se buscado novas fontes energéticas, de preferência que sejam 
renováveis e que possam garantir a sustentabilidade ambiental. Nesse contexto, a biomassa proveniente da gramínea capim-elefante (Pennisetum purpureum Schum), surge como uma cultura comumente utilizada na alimentação de animais e há alguns anos vem sendo estudada para fins energéticos (SILVA, 2010; FLORES et al., 2012).

O capim-elefante é originário da África, possui mais de duzentas variedades, algumas de alto rendimento e de boa qualidade para uso como fonte alternativa de energia (STREZOV et al., 2008). Pode ser utilizado na combustão direta, queimado em forma de briquetes ou pellets, na geração de energia térmica ou elétrica, em usos agrícolas e industriais que demandem calor.

As principais vantagens que podem ser destacadas no que tange o uso do capim-elefante com fonte energética são a sua alta produtividade, podendo chegar a 40 ton.ha ${ }^{-1}$. ano $^{-1}$ de massa seca; menor ciclo produtivo comparado a espécies florestais, permitindo até duas colheitas anuais; e assimilação mais eficiente do carbono (STREZOV et al., 2008; FLORES et al., 2012). Ademais destaca-se um sistema de produção desenvolvido, no qual a cultura pode ser facilmente produzida por meio de técnicas já consolidadas (BRAGA et al., 2013). No entanto, o capim-elefante apresenta alguns inconvenientes como elevada umidade pós-colheita e dificuldade de secagem natural. Além de sua baixa densidade a granel que inviabiliza o armazenamento e o transporte a maiores distâncias, necessitando de prévia compactação (SILVA, 2010).

A peletização é a forma mais atual para obtenção da biomassa compactada destinada ao uso energético. Os pellets apresentam menores dimensões, permitindo o uso de elementos transportadores e queimadores automáticos. Segundo Mani et al. (2006) os pellets tem como principais características a baixa umidade e maior densidade a granel em relação à biomassa de origem, o que otimiza o transporte, armazenamento e a geração de energia.
Nesse contexto, o objetivo do presente trabalho foi avaliar o efeito da umidade das partículas de capim-elefante na produção e qualidade de pellets.

\section{Material e Métodos}

\section{Matéria prima}

A biomassa proveniente de capim-elefante (Pennisetum purpureum Schum), composta por folhas e caules, foi obtida a partir de um plantio com cinco meses de idade pertencente ao Departamento de Zootecnia da Universidade Federal de Viçosa, localizada nas coordenadas $20^{\circ} 45^{\prime} 14^{\prime \prime} \mathrm{S}$ e $42^{\circ} 52^{\prime} 54^{\prime \prime} \mathrm{W}$.

Após a colheita, o material foi submetido a uma pré-secagem em temperatura ambiente, em seguida foi triturado em moinho martelo e classificado em peneira com abertura de 2 $\mathrm{mm}$ de diâmetro, obtendo partículas com tamanho adequado para as condições de peletização disponíveis.

\section{Produção dos pellets}

As partículas foram secas em estufa de circulação forçada a $103 \pm 2{ }^{\circ} \mathrm{C}$ até atingirem a umidade definida para os tratamentos, Tabela 1.

Tabela 1. Identificação dos tratamentos realizados no presente estudo.

Table 1. Identification of the treatments performed in this study.

\begin{tabular}{cc}
\hline $\begin{array}{c}\text { Identificação do } \\
\text { tratamento }\end{array}$ & $\begin{array}{c}\text { Umidade das partículas } \\
\text { para peletização }\end{array}$ \\
\hline $\mathrm{T} 1$ & $10 \pm 0,5 \%$ \\
$\mathrm{~T} 2$ & $12 \pm 0,5 \%$ \\
$\mathrm{~T} 3$ & $14 \pm 0,5 \%$ \\
$\mathrm{~T} 4$ & $16 \pm 0,5 \%$ \\
\hline
\end{tabular}

Os pellets foram produzidos em uma prensa peletizadora laboratorial da marca Amandus Kahl, modelo $14-175$ com capacidade para produção de $50 \mathrm{~kg} \cdot \mathrm{h}^{-1}$. A matriz de peletização possui orifícios com comprimento de $30,0 \mathrm{~mm}$ e diâmetro de 
7,5 mm na entrada e $6,3 \mathrm{~mm}$ na saída, a faca que define o tamanho dos pellets está posicionada a $20 \mathrm{~mm}$ da matriz.

Foram produzidos aproximadamente 3,0 kg de pellets por tratamento a uma temperatura média de $95^{\circ} \mathrm{C}$.

\section{Propriedades do capim-elefante e dos pellets}

Para a determinação da umidade de equilíbrio higroscópico das partículas e dos pellets, as amostras foram colocadas em uma câmara climática por um período de 30 dias, a $20^{\circ} \mathrm{C}$ de temperatura e $65 \%$ de umidade relativa do ar até atingirem massa constante. A umidade em base seca foi determinada de acordo com a norma da Associação Brasileira de Normas Técnicas - NBR 7993 (ABNT, 1983).

A densidade a granel $\left(\mathrm{kg} / \mathrm{m}^{3}\right)$ das partículas e dos pellets foi obtida de acordo com a norma Deutsches Institut Fur Normung - EN 15103 (DIN, 2010a). O incremento em massa por unidade de volume foi obtido dividindo-se a densidade a granel dos pellets pela densidade a granel da biomassa. O diâmetro ( $\mathrm{mm})$ e comprimento $(\mathrm{mm})$ dos pellets foram obtidos seguindo a norma EN 16127 (DIN, 2012b).

A durabilidade mecânica e a porcentagem de finos dos pellets foram determinadas utilizando o equipamento LignoTester, Holmen', de acordo com a norma EN 15210-1 (DIN, 2010b). As amostras de pellets foram submetidas à ventilação por meio de um jato de ar que simula a destruição natural dos pellets durante o transporte e manuseio. Para a determinação da porcentagem de finos, o fluxo de ar tinha pressão de 30 mbar e duração de 30 segundos. Posteriormente, para determinação da durabilidade mecânica, as amostras sem finos foram submetidas a outro fluxo de ar de 70 mbar durante 60 segundos.

Para determinação do poder calorífico superior e teor de cinzas, as amostras foram transformadas em serragem, utilizando-se um moinho de facas, de acordo com a norma Techinical Association of the Pulp and Paper Industry - TAPPI 257 cm-85 (TAPPI, 1985). Foi utilizada a fração serragem que passou pela peneira com malha de 40 mesh e ficou retida na peneira com malha de 60 mesh. O teor de cinzas das partículas e dos pellets foi determinado de acordo com a norma NBR 8112 (ABNT, 1986). O poder calorífico superior das partículas e dos pellets foi obtido de acordo com a norma da EN 14918 (DIN, 2010c) e foi utilizado na estimativa do poder calorífico útil, conforme a Equação 1, Anexo E da norma EN 14918 (DIN, 2010c).

PCU (pressão constante $)=\left(P C S-212,2{ }^{\star} H \quad\right.$ Equação 1
$\left.-0,8^{\star}(\mathrm{O}+\mathrm{N})\right)^{\star}\left(1-0,01{ }^{\star} \mathrm{M}\right)-\left(24,43^{\star} \mathrm{M}\right)$

Onde: PCU (pressão constante): poder calorífico útil em pressão constante, em J.g ${ }^{-1}$;PCS: poder calorífico superior, em J.g-1 ; H, O, N: hidrogênio, oxigênio e nitrogênio, respectivamente, em porcentagem (\%); M: umidade, base úmida, em porcentagem (\%); Constantes: A energia de vaporização (pressão constante) para a água a $25^{\circ} \mathrm{C}$ é de $44,01 \mathrm{~kJ} \cdot \mathrm{mol}^{-1}$. Isto corresponde a $218,3 \mathrm{~J} \cdot \mathrm{g}^{-1}$ para $1 \%$ de hidrogênio $(\mathrm{m} / \mathrm{m})$ ou $24,43{\mathrm{~J} . \mathrm{g}^{-1}}$ para $1 \%$ de umidade $(\mathrm{m} / \mathrm{m})$ na amostra.

A densidade energética $\left(\mathrm{GJ} / \mathrm{m}^{3}\right)$ foi obtida por meio do produto do poder calorífico útil pela densidade a granel. O incremento energético foi obtido dividindo-se a densidade energética dos pellets pela densidade energética da biomassa.

Os pellets foram classificados de acordo com a norma EN 14961-6, em função do diâmetro, comprimento, umidade, cinzas, durabilidade mecânica, finos, poder calorífico útil e densidade a granel, Tabela 2. 
Tabela 2. Propriedades exigidas pela norma EN 14961-6 para pellets.

Table 2. Properties for pellets required by the EM 14961-6 standard.

\begin{tabular}{|c|c|c|c|}
\hline Parâmetro & Unidade & A & B \\
\hline $\begin{array}{l}\text { Diâmetro (D) e } \\
\text { Comprimento } \\
\text { (C) }\end{array}$ & $\mathrm{mm}$ & \multicolumn{2}{|c|}{$\begin{array}{c}\text { D06 a D10 } \Leftrightarrow 3,15 \leq C \\
\leq 40\end{array}$} \\
\hline Umidade & $\begin{array}{c}\% \text { base } \\
\text { seca }\end{array}$ & $\leq 13,6$ & $\leq 17,6$ \\
\hline Teor de cinzas & $\begin{array}{c}\% \text { base } \\
\text { seca }\end{array}$ & $\leq 5$ & $\leq 10$ \\
\hline $\begin{array}{l}\text { Durabilidade } \\
\text { mecânica }\end{array}$ & $\%$ & $\geq 97,5$ & $\geq 96,0$ \\
\hline Finos & $\%$ & $\leq 2,0$ & $\leq 3,0$ \\
\hline $\begin{array}{c}\text { Poder Calorífico } \\
\text { Útil }\end{array}$ & $\mathrm{MJ} / \mathrm{kg}$ & $\geq 14,1$ & $\geq 13,2$ \\
\hline $\begin{array}{c}\text { Densidade a } \\
\text { granel }\end{array}$ & $\mathrm{kg} / \mathrm{m}^{3}$ & $\geq 600$ & $\geq 600$ \\
\hline
\end{tabular}

Fonte: Adaptado de EN 14961-6 (DIN, 2012a)

\section{Análise estatística}

O experimento foi instalado segundo um delineamento inteiramente casualizado, com quatro tratamentos (umidades das partículas para a produção dos pellets).

Os dados foram submetidos aos testes Cochran e Lilliefors para avaliar a homogeneidade e normalidade das variâncias, respectivamente. Posteriormente, procedeu-se a análise de variância ANOVA e quando estabelecidas diferenças significativas, os tratamentos foram comparados entre si por meio do teste de Tukey a 95\% de nível de confiança.

\section{Resultados e Discussão}

Observa-se a redução da umidade de equilíbrio higroscópico dos pellets para os tratamentos que utilizaram partículas com menor umidade, Figura 1.

Todos os tratamentos apresentaram valor de umidade de equilíbrio higroscópico inferior à exigida pela norma de pellets, que especifica valor máximo de 13,6\% em base seca. Para a biomassa energética quanto menor o teor de umidade, maior é a energia útil liberada na combustão.

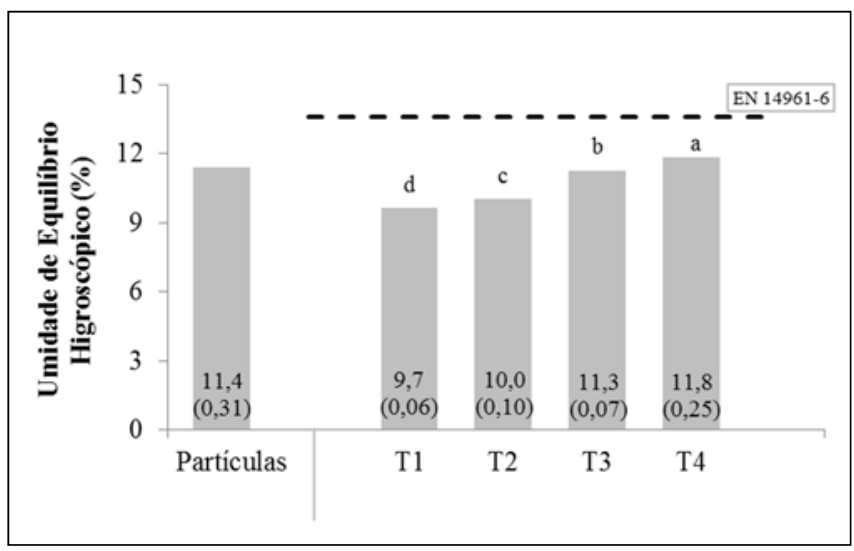

Figura 1. Umidade de equilíbrio higroscópico para as partículas e pellets.

Figure 1. Equilibrium moisture content of particles and pellets.

Valores médios apresentados são seguidos pelo respectivo desvio-padrão entre parênteses. Médias seguidas da mesma letra minúscula não diferem entre si a $5 \%$ de probabilidade de erro pelo teste Tukey. Linha tracejada corresponde ao valor máximo de umidade estipulado pela norma EN14691-6.

Uma menor umidade contribui de forma positiva para o aumento do poder calorífico útil, uma vez que a água presente na biomassa reduz a geração de energia no momento da combustão. De modo geral, a redução da umidade para pellets promove um aumento significativo em sua resistência mecânica, diminuindo a geração de finos durante o transporte e armazenamento. Além disso, dificulta a ocorrência e degradação por microrganismos decompositores da madeira quando armazenados por longos períodos de tempo (LIU et al., 2014).

O capim-elefante é um tipo de gramínea denominada como volumosa no setor agropecuário, isso devido à sua baixa densidade a granel. Neste trabalho, foi encontrado valor médio de $146,2 \mathrm{~kg} / \mathrm{m}^{3}$, na umidade de 11,4\% em base seca, Figura 2. A sua baixa densidade a granel inviabiliza o transporte a maiores distâncias por ocupar grandes volumes, além do baixo conteúdo energético contido por unidade volumétrica, 
características presentes na maioria das biomassas de origem vegetal (NHUCHHEN et al., 2014).

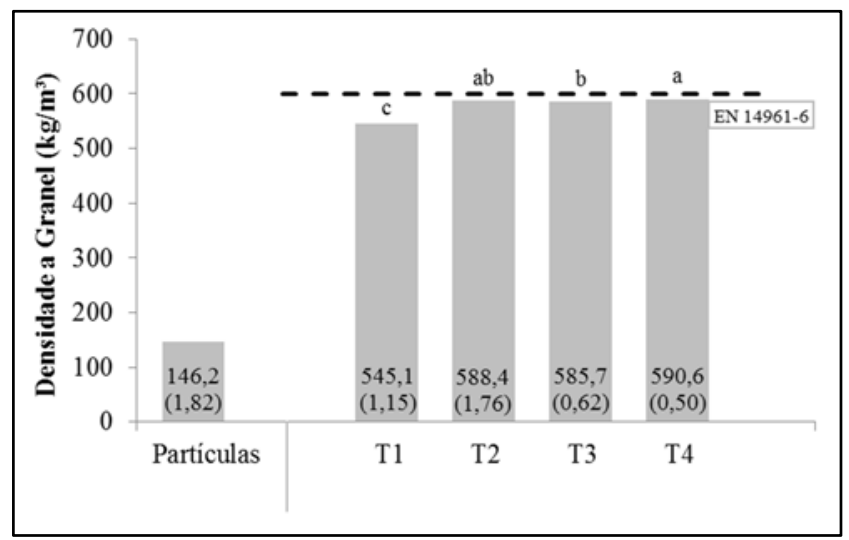

Figura 2. Densidade a granel para as partículas e pellets.

Figure 2. Bulk density for particles and pellets.

Valores médios apresentados são seguidos pelo respectivo desvio-padrão entre parênteses. Médias seguidas da mesma letra minúscula não diferem entre si a $5 \%$ de probabilidade de erro pelo teste Tukey. Linha tracejada corresponde ao valor mínimo de densidade a granel estipulado pela norma.

Verificou-se, de modo geral, um aumento da densidade a granel em função do aumento do teor de umidade das partículas. Isto se deve ao teor de umidade inicial das partículas do capim-elefante que influenciou na capacidade de compactação e na expansão dos pellets durante o resfriamento, o que afeta diretamente seu volume e consequentemente sua densidade. A norma de pellets exige valores mínimos de $600 \mathrm{~kg} / \mathrm{m}^{3}$, logo nenhum dos tratamentos obteve valor adequado.

Apesar de não atingir ao valor mínimo de densidade a granel, vale salientar que houve um incremento de massa por unidade de volume na ordem de 4 vezes em relação as partículas de capim-elefante não compactada. Tal fato contribui para uma maior densidade energética, viabiliza transporte a maiores distâncias e otimiza o espaço em locais de armazenagem (KALIYAN; VANCE MOREY, 2009).

O diâmetro dos pellets variou entre 6,24 a 6,35 mm, sendo o maior valor observado para aqueles produzidos com maior teor de umidade, provavelmente devido a maior expansão no sentido transversal ocasionada pela saída dos vapores de água durante o resfriamento, Figura 3A. Não foi observada diferença significativa para o comprimento dos pellets nos diferentes tratamentos, sendo encontrado valor médio de 20,6 mm, Figura 3B. As dimensões dos pellets, diâmetro e comprimento, obtidas neste experimento, independente dos tratamentos atenderam ao especificado na norma para pellets.

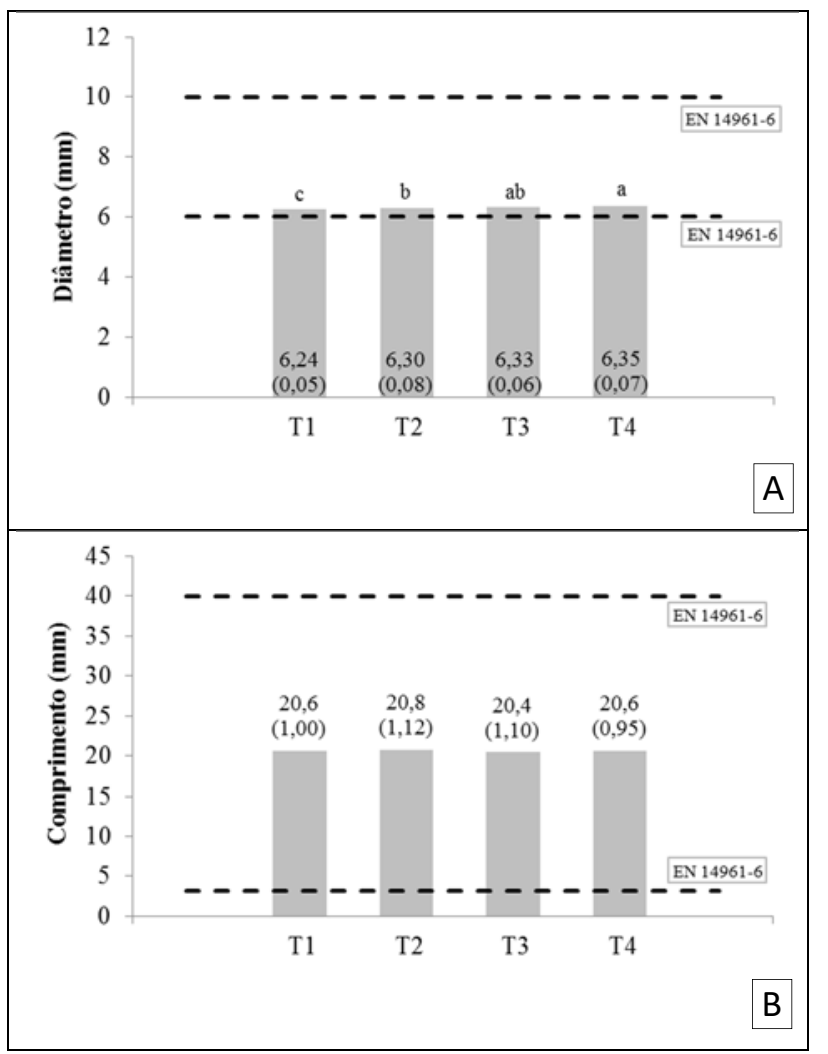

Figura 3. Diâmetro (A) e comprimento (B) dos pellets produzidos.

Figure 3. Diameter (A) and length (B) of pellets produced. Valores médios apresentados são seguidos pelo respectivo desvio-padrão entre parênteses. Médias seguidas da mesma letra minúscula não diferem entre si a $5 \%$ de significância pelo teste Tukey. Linha tracejada corresponde aos valores mínimo e máximo de diâmetro estipulado

A resistência mecânica dos pellets foi medida por meio da porcentagem de finos e da durabilidade, sendo desejável menor valor para finos e maior para a durabilidade (LARSSON; RUDOLFSSON, 2012). Verificou-se um aumento significativo da durabilidade mecânica dos pellets com o aumento do teor de umidade e como consequência observou-se uma menor geração de finos, Figura 4. 


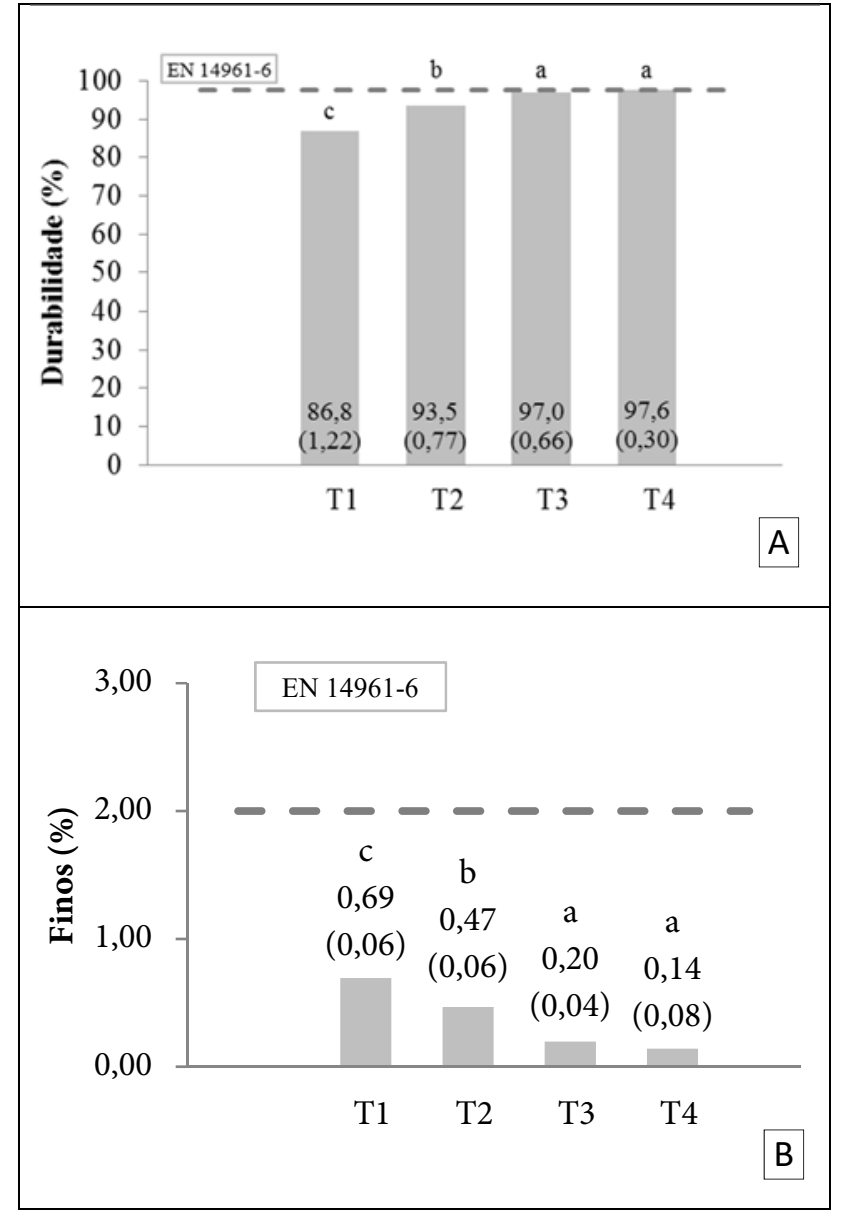

Figura 4 - Durabilidade (A) e finos (B) dos pellets produzidos.

Figure 4 - Durability (A) and fines (B) of pellets produced.

Valores médios apresentados são seguidos pelo respectivo desvio-padrão entre parênteses. Médias seguidas da mesma letra minúscula não diferem entre si a $5 \%$ de significância pelo teste Tukey. Linha tracejada corresponde ao valor máximo para finos e valor mínimo para durabilidade mecânica, segundo norma EN 14961-6.

A quantidade de finos gerados pelos pellets, independente do tratamento, ficou abaixo do máximo permitido pela norma de pellets que estipula valores inferiores a 3\%. Para a durabilidade mecânica apenas os pellets produzidos com partículas contendo $16 \%$ de umidade atenderam a especificação da norma, apresentando valor médio de 97,6\%.

A resistência mecânica de pellets é de grande importância no momento do transporte e armazenamento, as quais são atividades que em algum momento são empregadas máquinas para movimentação da massa de pellets ou no caso do transporte que são constantemente submetidos a esforços e às condições das estradas (KALIYAN; VANCE MOREY, 2009).

Foi observado teor médio de cinzas de $10,9 \%$ para os pellets de capim-elefante. A norma EN 14961-6 estipula valor máximo de $10 \%$ para pellets destinados ao uso não industrial. Salienta-se que altos teores de cinzas, além de reduzir o poder calorifico superior, são prejudiciais aos processos de queima, pois causam incrustações nas câmaras de combustão, corrosão de tubulações e demais equipamentos, além da geração de resíduos (NHUCHHEN et al., 2014).

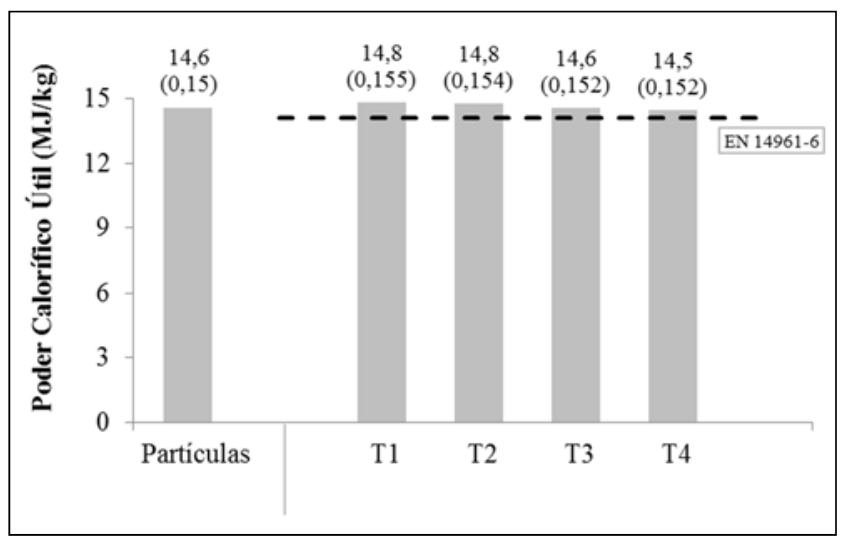

Figura 5. Poder calorífico útil para as partículas e pellets. Figure 5. Net calorific value for particles and pellets. Valores médios apresentados são seguidos pelo respectivo desvio-padrão entre parênteses. Linha tracejada corresponde ao valor mínimo de poder calorífico útil estipulado pela norma.

Foi observado para as partículas de capim-elefante o valor médio de poder calorífico útil (PCU) de 14,6 MJ/kg na umidade de $11,4 \%$. Não houve efeito do teor de umidade das partículas utilizadas para a produção dos pellets no poder calorifico útil dos mesmos, em função da pequena variação entre as umidades testadas, obtendo valor médio para o PCU de 14,7 $\mathrm{MJ} / \mathrm{kg}$. Todos os tratamentos obtiveram valor de PCU superior ao mínimo exigido pela norma de pellets, Figura 5.

O poder calorifico útil considera a energia necessária para evaporar a água e tem relação direta com a quantidade de energia liberada durante a combustão da biomassa (SANTOS, 
2010). Ademais, seu incremento contribui de forma positiva para o aumento da densidade energética (PEREIRA, 2014).

Observa-se, na Figura 6, o aumento da densidade energética dos pellets em relação às partículas de capim-elefante, devido ao processo de compactação promover o aumento da densidade a granel, consequentemente, um incremento da quantidade de energia por unidade de volume. $\mathrm{O}$ incremento energético foi da ordem de 4 vezes, mostrando que o processo de peletização gera um produto mais competitivo frente aos atuais combustíveis utilizados que apresentam alta densidade energética.

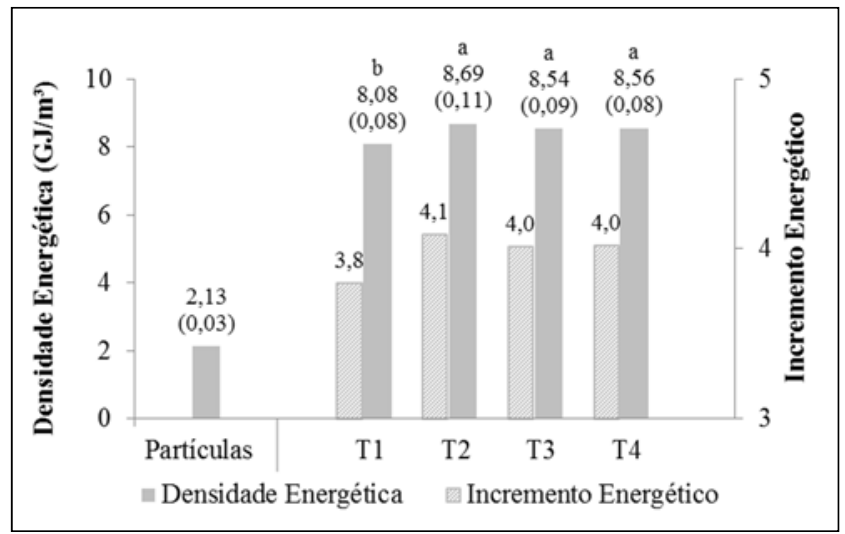

Figura 6. Densidade energética para as partículas e pellets e incremento energético função dos tratamentos.

Figure 6. Energy density for particles and pellets and energy increase the treatments.

Valores médios apresentados são seguidos pelo respectivo desvio-padrão entre parênteses. Médias seguidas da mesma letra minúscula não diferem entre si a 5\% de significância pelo teste Tukey.

Segundo Pereira (2014) a densidade energética permite avaliar o potencial de determinada biomassa para geração de energia. Seu aumento contribui positivamente para a otimização do transporte, reduzindo custos e aumentando o raio de abrangência (OBERNBERGER; THEK, 2010). Além de liberar maior quantidade de energia por unidade de volume durante a combustão da biomassa.

\section{Conclusões}

O capim-elefante apresenta grande potencial para produção de pellets, necessitando de novos estudos de aditivos ou técnicas de pré-tratamento das partículas que aumentem a densidade a granel e a durabilidade dos pellets.

A peletização promoveu um significativo aumento da densidade energética do capim-elefante, viabilizando transporte a maiores distâncias, otimizando o armazenamento e a geração de energia para um mesmo volume.

De modo geral, pellets produzidos com partículas a \pm $12,0 \%$ de umidade obtiveram melhores resultados para as propriedades físicas, químicas, mecânicas e maior densidade energética.

\section{Referências}

ABNT - ASSOCIACAO BRASILEIRA DE NORMAS TÉCNICAS. NBR 7993: madeira: determinação da umidade por secagem em estufa reduzida a serragem Método de ensaio. Rio de Janeiro, 1983.

ABNT - ASSOCIACAO BRASILEIRA DE NORMAS TÉCNICAS. NBR 8112: Análise química imediata do carvão vegetal. Rio de Janeiro,: 8 p. 1986.

BRAGA, R. M.; MELO, D. M. A.; AQUINO, F. M.; FREITAS, J. C. O.; MELO, M. A. F.; BARROS, J. M. F.; FONTES, M. S. B. Characterization and comparative study of pyrolysis kinetics of the rice husk and the elephant grass. Journal of Thermal Analysis and Calorimetry, v. 115, n. 2, p. 19151920, 2013.

DIN - DEUTSCHES INSTITUT FUR NORMUNG. EN 14961-6: Solid biofuels - Fuel specifications and classes Part 6: Non-woody pellets for non-industrial use. Berlim: CEN: 16 p. 2012.

DIN - DEUTSCHES INSTITUT FUR NORMUNG. EN 16127: Solid biofuels - Determination of length and diameter of pellets. Alemanha: CEN: 11 p. 2012.

DIN - DEUTSCHES INSTITUT FUR NORMUNG. DIN EN 14918: Determination of calorific value. Belim: CEN: 63 p. 2010 . 
DIN - DEUTSCHES INSTITUT FUR NORMUNG. EN 15103: Solid biofuels - Determination of bulk density. Alemanha: CEN: 14 p. 2010.

DIN - DEUTSCHES INSTITUT FUR NORMUNG. EN 15210-1: Solid biofuels - Determination of mechanical durability of pellets and briquettes - Part 1: Pellets. Alemanha: CEN: 12 p. 2010.

FLORES, R. A.; URQUIAGA, S.; ALVES, B. J. R.; COLLIER, L. S.; BODDEY, R. M. Yield and quality of elephant grass biomass produced in the cerrados region for bioenergy. Engenharia Agrícola, v. 32, p. 831-839, 2012.

KALIYAN, N.; VANCE MOREY, R. Factors affecting strength and durability of densified biomass products. Biomass and Bioenergy, v. 33, n. 3, p. 337-359, 2009.

LARSSON, S. H.; RUDOLFSSON, M. Temperature control in energy grass pellet production - Effects on process stability and pellet quality. Applied Energy, v. 97, p. 24-29, 2012.

LIU, Z. G.; QUEK, A.; BALASUBRAMANIAN, R. Preparation and characterization of fuel pellets from woody biomass, agro-residues and their corresponding hydrochars. Applied Energy, v. 113, p. 1315-1322, 2014.

MANI, S.; TABIL, L. G.; SOKHANSANJ, S. Effects of compressive force, particle size and moisture content on mechanical properties of biomass pellets from grasses. Biomass and Bioenergy, v. 30, n. 7, p. 648-654, 2006.

NHUCHHEN, D. R.; BASU, P.; ACHARYA, B. A Comprehensive Review on Biomass Torrefaction. International Journal of Renewable Energy \& Biofuels, v. 2014, p. 56, 2014.

OBERNBERGER, I.; THEK, G. The pellet handbook: The production and thermal utilisation of pellets. London: Earthscan, 2010. 593 p.

PEREIRA, B. L. C. PROPRIEDADES DE PELLETS: BIOMASSAS, ADITIVOS E TRATAMENTO TÉRMICO 2014. 73 f. Tese (Doutorado em Ciência Florestal) Universidade Federal de Viçosa, Viçosa, MG, 2014.

SANTOS, R. C. D. Parâmetros de qualidade da madeira e do carvão vegetal de clones de eucalipto. 2010. 175 f. Tese (Doutorado em Ciência e Tecnologia da Madeira) Universidade Federal de Lavras, Lavras, MG, 2010.
SILVA, E. D. EUCALIPTO E CAPIM ELEFANTE: CARACTERÍSTICAS E POTENCIAL PRODUTIVO DE BIOMASSA. REVISTA AGROGEOAMBIENTAL, p. 10, 2010 .

STREZOV, V.; EVANS, T. J.; HAYMAN, C. Thermal conversion of elephant grass (Pennisetum Purpureum Schum) to bio-gas, bio-oil and charcoal. Bioresource Technology, v. 99, n. 17, p. 8394-8399, 2008.

TAPPI - TECHINICAL ASSOCIATION OF THE PULP AND PAPER INDUSTRY. T 257 cm-85: Sampling and preparing wood for analysis. Atlanta: TAPPI: 5 p. 1985. 